\title{
Kindling: a Model for the Development of Tardive Dyskinesia?
}

\author{
B. GLENTHØJ, ${ }^{1}$ R. HEMMINGSEN ${ }^{2}$ and T. G. BOLWIG ${ }^{1}$
}

'Department of Psychiatry, Rigshospitalet, DK-2100 Copenhagen, Denmark

${ }^{2}$ Department of Psychiatry, Copenhagen Municipal Bispebjerg Hospital

\begin{abstract}
Tardive dyskinesia (TD) from long-term neuroleptic treatment may be irreversible; therefore prevention has become a major concern. A controversial issue with regard to the clinical use of neuroleptic drugs is the possible influence on the development of TD of drug holidays. The major characteristics of kindling, theories of TD and the role of multiplicity in the development of TD are described. Some clinical studies point to interruption of neuroleptic therapy being a risk factor for development of irreversible TD. Induction of dyskinesia in non-human primates has been demonstrated after repeated administration of haloperidol. Rodent studies have not been conclusive. Several experimental results link TD with kindling: both conditions involve repeated stimulations, both seem to involve increased receptor responsiveness and in both conditions does depression in GABA transmission in SNR (substantia nigra; pars reticulata) play an important role. It is concluded that the kindling hypothesis is relevant to the investigation of TD.
\end{abstract}

Kindling refers to the progressive development of neuronal after-discharges following repeated electrical stimulation of a given brain site with an initially subthreshold current (Goddard et al., 1969). This eventually leads to increasingly complex behavioural and electrical manifestations which typically culminate in a major motor seizure. The kindling phenomenon has also been connected with the progressive development of pathological behaviour in a group of neuro-psychiatric conditions including alcohol withdrawal (Clemmesen and Hemmingsen, 1984).

Tardive dyskinesia (TD) as defined by Casey (Casey, 1984) is an abnormal motor system disorder characterized primarily by involuntary repetitive movements of the tongue, mouth and facial muscles, sometimes accompanied by limb and truncal choreoathetosis. It occurs in predisposed individuals during or following cessation of prolonged neuroleptic treatment, and may persist. The symptoms are accentuated by termination of the medication, and it has been proposed, that repeated episodes of neuroleptic drug withdrawal lead to a kindling-like facilitation of receptor sensitivity following each subsequent withdrawal (Post and Ballenger, 1981).

The purpose of the present paper is to review the essential clinical and experimental evidence about the mechanisms of kindling and TD in order to evaluate if sufficient overlap exists to justify further studies of kindling as a model for TD.

$0953-4180 / 88 / 010029+12 \$ 3.50 / 0 \quad$ (C) 1988 CNS (Clinical Neuroscience) Publishers 


\section{Major characteristics of electrical kindling}

According to the original description (Goddard et al., 1969; Post and Ballenger, 1981; Wada et al., 1974; Racine, 1972) the kindling procedure involves:

1 Repeated stimulations

2 Local after-discharges and seizure activity

(a) Increase in amplitude

(b) Increase in duration

(c) Increase in complexity and wave form

(d) Increase in anatomical spread from limbic structures into the striatum and brain stem and finally into the cerebral cortex

3 Replicable sequence of seizure stages through the following classes:

(1) Facial clonus involving masticatory movements

(2) Head nodding

(3) Forelimb clonus

(4) Rearing

(5) Rearing and falling

4 Regional differences in sensitivity, limbic structures being the most sensitive.

5 Optimal stimulus interval 24 hours -7 days.

6 Permanent change. A kindled animal will still seize after a 1-year seizure free interval.

To explain kindling the following mechanisms have been suggested (McNamara et al., 1980):

(1) Sprouting neuronal collaterals

(2) Increased synaptogenesis

(3) Dendritic swelling

(4) Presynaptic terminal enlargement

Kindling results in a long-term enhancement of evoked potentials in multiple brain regions in response to a constant test stimulus in the kindled amygdala (McNamara et al., 1980; Racine et al., 1972). Electrophysiological studies have shown long-term potentiations of synapses (Racine et al., 1972; Douglas and Goddard, 1975; Goddard and Douglas, 1975; Bliss, 1979), and an increased excitability of the postsynaptic neurons has been found (Goddard, 1983).

\section{Involvement of neutrotransmittor systems in kindling}

Catecholamines are believed to be inhibitory to the development of amygdaloid kindling (Corcoran et al., 1974; Adamec and Stark-Adamec, 1983), but various investigations as to the status of catecholaminergic neurons after amygdala kindling are conflicting (Adamec and Stark-Adamec, 1983; Gee et al., 1980, 1981, 1983; Engel and Sharpless, 1977; Farjo and Blackwood, 1978; Wilkison and Halpern, 1979). Long-lasting depletion of dopamine 
(Engel and Sharpless, 1977), reduction in DA receptor binding (Gee et al., 1980, 1981, 1983), and reduction in tyrosine hydroxylase activity (Farjo and Blackwood, 1978) in the rat amygdala have been found in kindled rats, but later reports (Adamec and Stark-Adamec, 1983; Wilkison and Halpern, 1979) suggest an increase in DA activity following kindling.

It is of interest that rodents kindled in the presence of $0.25 \mathrm{mg} / \mathrm{kg}$ of haloperidol (Gee et al., 1983), (but not 0.5 or $1 \mathrm{mg} / \mathrm{kg}$ ) developed seizures with a significantly lower number of stimulations than did non-treated controls. This is in agreement with other observations (Babington and Wedeking, 1973; Sato et al., 1978). These data suggest that the presence of low levels of haloperidol facilitate seizure development.

In a study of limbic kindling and animal behaviour Adamec and StarkAdamec (1983) suggest that epileptogenicity and synaptic changes may be independent processes resulting from kindling, and that behavioural changes do not require the development of motor convulsions. Furthermore, they propose that long-lasting synaptic potentiation and increased susceptibility to failure under high drive of neurotransmitter systems antagonistic to seizure expressions (including dopamine) are mechanisms underlying the persisting interictal changes in behaviour in humans with complex partial epilepsy. Also the paradoxical relationship between seizures and psychopathology may be understood his way.

Also the relationship between the development of TD, the antipsychotic effect of neuropleptica and psychopathology are closely related. The complementary view of schizophrenia as a disorder of reinforcement dates from different authors (Stein and Wise, 1971; Crow and Deakin, 1985; Miller, 1984). Dopamine, either alone or in co-operation with other transmitter systems, mediates the reinforcing effects of brain stimulation (Crow and Deakin, 1985), and a kindling-like stimulation of dopaminergic systems has been proposed as a model of psychosis (Post et al., 1976; Post and Ballenger, 1981a; Post et al., 1981). Kindling stimulation of the central tegmental area of the cat (Stevens and Livermore, 1978) speaks in favour of this hypothesis, in so far as the animals developed progressive fearfulness and loss of social behaviour instead of seizures.

Kindling of the amygdala and nucleus accumbens (Ehlers and Kvole, 1985) has produced decrease in spontaneous post-itcal locomotion and interictal spontaneous and amphetamine-induced locomotion. In agreement with this, Post and Ballenger (1981) have reported decreased spontaneous vertical rearing activity, as well as decreased cocaine-induced vertical activity after amygdala kindling. In contrast, the animals in the latter study were more reactive to the direct dopamine receptor agonist apomorphine, and Post suggested that a possible primary dopamine depletion would produce a compensatory increase in dopamine depletion receptor sensitivity. Also, Adamec has reported behavioural changes after kindling of the amygdala and hippocampus (Adamec, 1975a,b). However, it still remains to be clarified whether dopaminergic synapses are potentiated following repetitive activation by either stressful events or electric kindling. With the established kindling model in our laboratory (Clemmesen and Hemmingsen, 
1984; Barry et al., 1987) we hope to be able to do this by ongoing studies of electrical kindling of dopaminergic regions in the rat.

Engel and colleagues (1978) point to the possible existence of a separate system for generation of local afterdischarges independent of seizuregenerating mechanisms. They found no correlation between afterdischarge duration and the severity of behavioural seizures. Increased glucose uptake in certain structures with increased glucose metabolism during the various stages of amygdaloid kindling in rats were identified by ${ }^{11} \mathrm{C}$-2-deoxyglucose (DG) autoradiographic technique. Partial (stages 1 and 2) seizures were correlated with increased DG uptake in the ipsilateral amygdala and its direct projection fields, suggesting that the behavioural symptoms manifested during the early stages of kindling result from excessive activity within the amygdala and its immediate efferent projection. When the rats reached the third stage of kindled seizures DG uptake rose in substantia nigra (SN). This is especially interesting compared with the studies of Nevander (1985) showing a primary hypermetabolism during seizures in SN followed by hypometabolism. Nevander hypothesizes that SN is central in seizure control.

Iadarola and Gale (1982) have reported that local injection of gammaaminobutyric acid (GABA) into SN provides protection against electrically and chemically induced seizures without a widespread augmentation of GABA-mediated activity throughout the brain. Also, they conclude that synapses in SN represent an important control mechanism for inhibiting the propagation of generalized convulsions.

In agreement with this interpretation is the finding that bilateral microinjection of the GABA agonist muscimol into the substantia nigra, pars reticulata (SNR) suppresses kindled motor seizures and limbic seizures (McNamara et al., 1983), and the observation that the activity of a marker of GABA neurons, glutamic acid decarboxylase (GAD), is significantly lower in $\mathrm{SN}$ of amygdala-kindled rats compared to non-kindled rats (Löscher and Schark, 1985).

These results point to the possibility that a reduction of endogenous GABAergic neuronal communication in SN plays a fundamental role in the enhanced excitability of kindling. This again raises the question as to which afferent and efferent pathways from the substantia nigra could be involved in the case of amygdaloid kindling. Amygdala receives direct dopaminergic projections from SN (Meibach and Katzman, 1981; Ottersen, 1981), and there are direct afferents from the amygdala to SN (Ottersen, 1981). Löscher (Löscher and Schark, 1985) mentions the possibility that the loss of GAD in the nigra measured in amygdala-kindled rats could be mediated via direct projections from the amygdala to $\mathrm{SN}$ or via the afferents from the amygdala to the corpus striatum.

\section{Theories of tardive dyskinesia}

The most prominent hypothesis explaining TD has been that of dopamine (DA) receptor hypersensitivity (for further information see Casey et al., 
1985, and Fann et al., 1980). However, several aspects of TD do not support the DA hypersensitivity theory. All rodents treated with DA receptor antagonists show behavioural and biochemical hypersensitivity of DA receptors (Casey, 1986), and the changes are reversible after discontinuing administration of neuroleptics (Rupniak et al., 1983). TD has a late onset and a possible irreversible course, it occurs without agonist provocation and only in predisposed individuals (Casey, 1986). In a recent study Waddington et al. (1986) found, that those orofacial movements which occurred to excess in long-term neuroleptic treatment in rats were chronologically dissociable from dopamine receptor supersensitivity and from dopaminergic hyperfunction in general.

Scheel-Krüger (1986) suggests that the syndrome of TD may involve an imbalance between the dopamine systems and/or the GABA systems. Blockade of dopamine receptors (by 6-hydroxydopamine lesion of the nigrastratal dopamine system or chronic neuroleptic application) induces functional supersensitivity of SNR neurons (GABA-ergic supersensitivity) monitored electro-physiologically or assessed by behavioural changes induced by intracerebral injection of GABA agonist into the SNR (ScheelKruger, 1986; Waszczak et al., 1984; Coward, 1982; Gale and Casu,; 1981; Arnt and Scheel-Krüger, 1979).

This interpretation agrees with the observations of Gunne and his colleagues (Gunne et al., 1984) of a decrease in GAD in substantia nigra; this appeared only in monkeys which developed "tardive dyskinesia" during chronic neuroleptic treatment. Findings of Arnt and Scheel-Krüger (1980) of very intense dyskinetic oral activity after local injection of GABA antagonists into the SNR likewise indicates an involvement of the GABAsystem in TD.

\section{Experimental models for tardive dyskinesia}

Casey holds that three general types of animal models play an important role in TD-research: the homologous models, the analogous models and correlational models (Casey, 1984). The only homologous animal model of TD is to be found in non-human primates with persisting orofacial and limb dyskinesias induced by extended neuroleptic treatment. Unfortunately work with this model is very expensive.

Recent studies (Waddington et al., 1986; Clow et al., 1979, 1980; Gunne et al., 1982; Waddington et al., 1983, 1985) report that rodents receiving prolonged neuroleptic treatment may develop spontaneous mouthing (vacuous chewing and/or lateral side-to-side jaw movements which may involve teeth grinding). This syndrome appears to show several characteristics of TD. It is evident in a proportion of animals only (Waddington et al., 1985), it is more often seen in older than in younger animals (Waddington et al., 1985,1986 ), and the orofacial movements persist and tend to increase after discontinuation of neuroleptic treatment (Waddington et al., 1985). This model might according to Casey qualify as analogous. 
Behavioural hypersensitivity in the form of increased response to DA agonists following DA antagonist treatment and biochemical changes of increased numbers of D2 receptors in treated animals are widely used animal models in TD research, but as mentioned several aspects of TD do not support the DA hypersensitivity theory, and the model does not even qualify as a correlational model.

\section{Role of multiplicity}

One of the most controversial issues that currently exists with regard to the clinical use of neuroleptic drugs is the possible influence on the development of TD of drug holidays. Chronic exposure of experimental animals to neuroleptic drugs produces tolerance to the eataleptic effects of these drugs, as well as an increase in striatal dopamine receptors. The development of tolerance has been connected with TD, but this is most uncertain, and one might also connect TD with sensitization (increases in susceptibility to some drug effects).

Many compounds which directly or indirectly activate dopaminergic receptors have been reported to induce progressive effects on hyperactivity or stereotypy in animals (Casey, 1984). Thus, both amphetamine rechallenge and apomorphine testing have demonstrated that intermittent pretreatment with amphetamine caused a markedly more pronounced increase in stereotypy than did continuous administration (Nelson and Ellison, 1978), and several studies with cocaine and L-dopa have also shown increase in susceptibility to the side-effects after repetitive administration (Post and Ballenger, 1981; Post and Rose, 1976; Post et al., 1976; Stipling and Ellinwood, 1977; Klawans et al., 1977). Observations by Post and co-workers (Post and Ballenger, 1981) suggest that this effect on behaviour of repetitive cocaine administration may be inhibited by simultaneous lithium administration. They point to the possibility that lithium may block some behavioural and biochemic indices of stimulant-induced sensitization, as it appears to block the development of neuroleptic withdrawal supersensitivity (Pert et al., 1978; Gallager et al., 1978). Post and Ballenger (1981) suggested that repeated episodes of neuroleptic withdrawal, which produce dopamine receptor supersensitivity might lead to a kindling-like facilitation of receptor sensitivity following each neuroleptic withdrawal.

Recently, the importance of treatment schedule of neuroleptics in the development of DAergic supersensitivity has been recognized in a number of rodent studies (Sant and Ellison, 1984; Belmaker et al., 1985; Carey and DeVeaugh-Geiss, 1984; Koller, 1984; Kashira et al., 1984; Murugaiah et al., 1985; Sant and Ellison, 1984), but the conclusions do not agree with each other, and the results are very difficult to compare because of the differences in treatment schedules. Furthermore, spontaneous mouthings have not been counted in any of the studies except one (Sant and Ellison, 1984). This study suggested that drug holidays might play a role in the time-course of neuroleptic-induced TD.

Dyskinetic movements following repeated haloperidol administration 
have been reported by Weiss and Santelli (1978) in non-human primates. They treated monkeys weekly for 2 years with haloperidol. For the first 9 weeks of treatment they detected no significant effects of drug consumption, but after the tenth weekly dose dyskinetic movement disorders appeared $1 \mathrm{~h}$ to $8 \mathrm{~h}$ after drug administration. One of the monkeys had previously been maintained for a year on a regimen of $0.25 \mathrm{mg}$ of haloperidol $/ \mathrm{kg}$ on 5 days/ week without overt consequences.

The nature of these dyskinetic attacks warrants further exploration. The authors find that they might reveal the etiology of TD or other neurological disorders arising from disrupted neuropharmacologic function. What is important is the fact that dyskinetic movements can be induced by disrupted haloperidol treatment, but in as far as they occur few hours after medication, they might not represent TD.

Clinical studies (Waddington et al., 1986; Branchey and Branchey, 1984; Jeste et al., 1979) have suggested that persistent TD is associated with a greater number of interruptions of drug therapy.

Also of interest is the observation that affective disorders may be a risk factor for TD (Casey, 1986). Intermittent high dose short-term neuroleptic treatment may contribute to this.

\section{Comment}

If TD is a kindling-phenomenon, the question must be whether it results from behavioural sensitization to intermittent stimulation to neuroleptic drugs or from a kindling-like facilitation of receptor sensitivity following each subsequent neuroleptic withdrawal. A third possibility is the existence of an excessive responsiveness in the nigral output systems, as a result of the shown depression of GABA transmission in the SNR followed by functional supersensitivity of GABA receptors in the SNR. This may lead to a cumulative kindling effect by different unspecific (emotional?) stimuli from the limbic system. If this holds true, one might also expect a higher frequency of temporal lobe epilepsy in patients receiving intermittent neuroleptic therapy for a longer period of time! This can only be tested for in a prospective clinical study, in as far as psychoses seen in patients with temporal lobe epilepsy are commonly thought to be the result of the epilepsy.

As described above (Iadarola and Gale, 1982; McNamara et al., 1983; Löscher and Shark, 1985; Scheel-Krüger, 1986; Waszczak et al., 1984; Coward, 1982; Gale and Casu, 1981; Arnt and Scheel-Krüger, 1979) depressed GABA transmission in the SNR plays an important role both in the development of kindling-seizures and TD. This is in agreement with the kindling-hypothesis, but it does not clarify which of the three kindlingmechanisms is the most likely. The study by Weiss and Santelli (1978) could speak for behavioural sensitization to the drugs (the symptoms appeared already $1 \mathrm{~h}$ to $8 \mathrm{~h}$ after drug intake), but the fact, that termination of medication leads to accentuated dyskinetic symptoms speaks in favour of the facilitation of receptor sensitivity following neuroleptic withdrawal. 
There are other links between TD and kindling than the common reduction of endogenous GABAergic neuronal communication in SN. In the following the earlier described major characteristics of electrical kindling (cf. p. 30) will be compared with TD in sequential order:

1 Both conditions involve repeated stimulations.

2 Development of local after-discharges have to our best knowledge not been studied in TD.

3 Spontaneous mouthing in rats receiving prolonged neuroleptic treatment looks very much like the masticatory movements during class 1 seizures in kindling.

4 GAD is decreased in SN both in monkeys with "TD", in rats with neuroleptic-induced oral dyskinesia, and in kindled rats (Löscher and Schark, 1985; Gunne et al., 1984; Gunne and Häggström, 1983).

Besides development of facial stereotypies, including chewing movements, have beeen observed in connection with electrical kindling of the substantia nigra (Mintz and Herberg, 1985). Already Ferries (1886) reported torsion of the lip and semiclosure of the nostril on the same side following electrical irritation of the anterior and inner aspect of the uncinate gyrus. Temporal lobe seizures are often followed by mouth movements, and Baldwin et al. (1954) find in their clinical studies and in non-human primate studies that lip, face and jaw movements can be elicited by electrical stimulation of the amygdala.

5 The stimulus interval in TD is difficult to study before more is known about neuroleptics in vivo receptor-binding in the brain.

Recently quantitative dopamine-receptor binding studies in vivo in man have been performed by means of position emission tomography (PET) (Sedvall et al., 1986). These studies suggested that neuroleptics are eliminated very slowly from their binding sites in the brain. However, the relationship between visible binding and pharmacological and therapeutic effects remains to be clarified as does the role of relative drug withdrawal (subtotal receptor saturation) and possible imbalance between receptor subtypes.

6 Both kindling and TD once fully developed are considered to be rather permanent changes.

Another link between TD and kindling is the fact that both conditions seem to involve increased receptor responsiveness.

\section{Conclusion}

TD resulting from long-term neuroleptic treatment may be irreversible and unresponsive to treatment. Therefore prevention has become a major concern. One of the most controversial issues with regard to the clinical use of neuroleptic drugs is the possible influence on the development of TD of drug holidays. Clinical studies (Waddington et al., 1986; Branchey and Branchey, 1984; Jeste et al., 1979) have suggested that TD is associated with a greater number of interruptions of drug therapy, beside induction of 
dyskinesias in non-human primates by intermittent administration of haloperidol has been demonstrated (Weiss and Santelli, 1978). Rodent studies (Bannet et al., 1980; Belmaker et al., 1985; Carey and De Veaugh-Geiss, 1984; Koller, 1984; Kashira et al., 1986; Murugaiah et al., 1985; Sant and Ellison, 1984) have been difficult to compare because of the big differences in their respective treatment schedules, and there is as yet no decisive experimental evidence for or against an effect of drug holidays.

Post and Ballinger (1981) have proposed that repeated episodes of neuroleptic drug withdrawal lead to a kindling-like facilitation of receptor sensitivity following each subsequent withdrawal. Several experimental results link TD with kindling. Both TD and kindling seem to involve increased receptor responsiveness, and in both conditions does depression in GABA transmission in the SNR play an important role.

In further support is the fact that spontaneous mouthings in rats receiving prolonged neuroleptic treatment resemble the masticatory movements involved in class 1 seizures in kindling, and GAD is decreased in SN both in monkeys with "TD" and in kindled rats (Löschner and Schark, 1985; Gunne et al., 1984).

In conclusion the kindling hypothesis is relevant in the investigation of TD. The role of the treatment regimen and the neurobiologic mechanisms involved in the development of TD warrant further clinical and experimental investigations. The kindling hypothesis is a good starting point for such studies.

\section{References}

Adamec, R. E. (1975a). The natural basis of prolonged suppression of predatory attack. In: Naturally occuring physiological differences in limbic systems of killed and non-killed cats. Aggressive Behavior, 1, 315-330.

Adamec, R. E. and Stark-Adamec, C. (1983). Limbic kindling and animal behaviourimplications for human psychopathology associated with complex partial seizures. Biological Psychiatry, 18, 269-293.

Adamec, R. E. (1975b). Behavioral and epileptic determinants of predatory attack behavior in the cat. Canadian Journal of Neurological Science, 2, 457-466.

Arnt, J. and Scheel-Krüger, J. (1979). GABAergic and glycinergic mechanisms within the substantia nigra: Pharmacological specificity of dopamine-independent contralateral turning behaviour and interaction with other neurotransmitters. Psychopharmacology, 62, 267-77.

Arnt, J. and Scheel-Krüger, J. (1980). Intranigral GABA antagonists produce dopamineindependent biting in rats. European Fournal of Pharmacology, 62, 51-61.

Babington, R. G. and Wedeking, P. W. (1973). The pharmacology of seizures induced by sensitization with low intensity brain stimulation. Pharmacology, Biochemistry and Behaviour, $1,461-467$.

Baldwin, M., Frost, L. L. and Wood, C. D. (1954). Investigation of the primate amygdala. Movements of the face and jaws. Neurology, 4, 586-98.

Bannet, J., Belmarker, R. H. and Ebstein, R. P. (1980). The effect of drug holidays in an animal model of tardive dyskinesia. Psychopharmacology, 69, 223-4.

Barry, D. I., Kikvadze, I., Brudin, P., Bolwig, T. G., Björklund, A. and Lindvall, O. (1987). Grafted noradrenergic neurons suppress seizure development in kindling-induced epilepsy. Proceedings of the National Academy of Science, Washington, 84, 8712-8715. 
Belmaker, R. H., Elami, A. and Bannet, J. (1985). Intermittent treatment with droperidol, a short-acting neuroleptic, increases behavioural dopamine receptor sensitivity. In "Dyskinesia: Research and Treatment" (Eds D. E. Casey, T. Chase, A. V. Christensen and J. Gerlach). Springer, Berlin, 194-9.

Bliss, T. V. P. (1979). Synaptic plasticity in the hippocampus. Trends in Neuroscience, 2, 42-5.

Branchey, M. and Branchey, L. (1984). Patterns of psychotropic drug use and tardive dyskinesia. Fournal of Clinical Psychopharmacology, 4, 41-4.

Carey, R. J. and DeVeaugh-Geiss, J. (1984). Treatment schedule as a determinant of the development of tolerance to haloperidol. Psychopharmacology, 82, 164-7.

Casey, D. E. (1984). Tardive dyskinesia: New research. Psychopharmacology Bulletin, 20, 376-9.

Casey, D. C., Chase, R., Christensen, A. V. and Gerlach, J. (eds) (1985). "Dyskinesia: Research and Treatment". Springer, Berlin.

Casey, D. E. (1986). Tardive dyskinesia. In: "Psychopharmacology: A Generation of Progress". Raven Press. Under publication.

Clemmesen, L. and Hemmingsen, R. (1984). Physical dependence on ethanol during multiple intoxication and withdrawal episodes in the rat. Evidence of a potentiation. Acta Pharmacologica et toxicologica, 55, 345-50.

Clow, A., Jenner, P. and Marsden, C. D. (1979). Changes in dopamine-mediated behaviour during one year's neuroleptic administration. European Fournal of Pharmacology, 57, 36575.

Clow, A., Theororou, A., Jenner, P. and Marsden, C. D. (1980). Cerebral dopamine function in rats following withdrawal from one year of continuous neuroleptic administration. European Fournal of Pharmacology, 63, 145-57.

Corcoran, M. E., Fibiger, H. C., McCaughran, Jr, J. A. and Wada, J. A. (1974). Potentiation of amygdaloid kindling and metrazol-induced seizures by 6 -hyroxydopamine in rats. Experimental Neurology, 45, 118-133.

Coward, D. M. (1982). Classical and non classical neuroleptics induce supersensitivity of nigral GABA-ergic mechanisms in the rat. Psychopharmacology, 78, 180-4.

Crow, J. F. and Deakin, J. F. W. (1985). Neurochemical transmission, behaviour and mental disorder. In: "Handbook of Psychiatry", (Ed. M. Shepherd) Vol. 5, The Scientific Foundations of Psychiatry. Cambridge University Press, Cambridge.

Douglas, R. M. and Goddard, G. V. (1975). Long-term potentiation of the perforant pathbranule cell synapse in the rat hippocampus. Brain Research, 86, 205-15.

Ehlers, C. L. and Kvole, G. F. (1985). Locomotor behavior following kindling in three different brain sites. Brain Research, 326, 71-79.

Engel, Jr, J. and Sharpless, N. S. (1977). Long-lasting depletion of dopamine in the rat induced by kindling stimulation. Brain Research, 136, 381-386.

Engel, Jr, J., Wolfson, L. and Brown, L. (1978). Anatomical correlates of electrical and behavioural events related to amygdaloid kindling. Annals of Neurology, 3, 538-544.

Fann, W. E., Smith, R. G., Davis, J. M. and Domino, E. F. (1980). "Tardive Dyskinesia: Research and Treatment". Spectrum Publications, Jamaica.

Farjo, I. B. and Blackwood, D. H. R. (1978). Reduction in tyrosine hydroxylase activity in the rat amygdala induced by kindling stimulation. Brain Research, 153, 423-426.

Ferrier, D. (1886). "The Functions of the Brain", 2nd Ed. G. P. Putnam's Sons, New York. 244.

Gale, K. and Casu, M. (1981). Dynamic utilization of GABA in substantia nigra: regulation by dopamine and GABA in striatum, and its clinical and behavioural implications. Molecular and Cellular Biochemistry, 39, 369-404.

Gallager, D. W., Pert, A. and Bunney, W. E. Jr. (1978). Haloperidol-induced presynaptic dopamine supersensitivity is blocked by chronic lithium. Nature, 273, 309-12.

Gee, K. W., Killam, E. K., Holliger, M. A. and Giri, S. H. (1980). Effect of amygdaloid kindling on dopamine-sensitive adnylate cyclase activity in rat brain. Experimental Neurology, 70, 192-199.

Gee, K. W., Hollinger, M. A. and Killam, E. K. (1981). Effect of seizures kindled by subconvulsant doses of pentylenetetrazol on dopamine receptor binding and dopaminesensitive adenylate cyclase in the rat. Experimental Neurology, 74, 265-275. 
Gee, K. W., Killam, E. K. and Hollinger, M. A. (1983). Effects of haloperidol-induced dopamine receptor supersensitivity on kindled seizure development. Fournal of Pharmacology and Experimental Therapeutics, 22, 70-76.

Goddard, G. V. (1982). Separate analysis of lasting alteration in excitatory synapses, inhibitory synapses and cellular excitability in association with kindling. Electroencephalography and Clinical Neurophysiology (Supplement), 36, 288-94.

Goddard, G. V. and Douglas, R. M. (1975). Does the engram of kindling model the engram of normal long term memory? Canadian Journal of Neurological Science, Nov, 385-94.

Goddard, G. V., McIntyre, D. C. and Leech, C. K. (1969). A permanent change in brain function resulting from daily electrical stimulation. Experimental Neurology, 25, 295-330.

Gunne, L. M., Growdon, J. and Glaeser, B. (1982). Oral dyskinesia in rats following brain lesions and neuroleptic drug administration. Psychopharmacology, 77, 134-9.

Gunne, L. M. and Häggström, J. E. (1983). Reduction of nigral glutamic acid decarboxylase in rats with neuroleptic induced oral dyskinesia. Psychopharmacology, 81, 191-4.

Gunne, L. M., Häggström, J.E. and Sjöquist, B. (1984). Association with neurolepticinduced dyskinesia of regional changes in GABA synthesis. Nature, 309, 347-9.

Iadarola, M.J. and Gale, K. (1982). Substantia nigra: site of anticonvulsant activity mediated by gamme-aminobutyric acid. Science, 218, 1237-40.

Jeste, D. V., Potkin, S. G., Sinha, S., Feder, S., Wyatt, R. J. (1979). Tardive dyskinesia -... reversible and persistent. Archives of General Psychiatry, 36, 585-90.

Kashira, K., Sato, M., Fujiwara, Y., Harada, T., Ogawa, T. and Otsuki, S. (1986). Effect of intermittent and continuous haloperidol administration on the dopaminergic system in the rat brain. Biological Psychiatry, 21, 650-6.

Klawans, H. L., Goetz, G., Nausilda, P.A. and Weiner, W. J. (1977). Levodopa-induced dopamine receptor hypersensitivity. Annals of Neurology, 2, 125-9.

Koller, W. C. (1984). Effects of intermittent haloperidol treatment on dopamine receptor sensitivity in guinea pigs. Psychopharmacology, 84, 98-100.

Löscher, W. and Schark, W.S. (1985). Evidence for impaired GABAenergic activity in the substantia nigra of amygdaloid kindled rats. Brain Research, 339, 146-50.

McNamara, J. O., Byrne, M. G., Dasheiff, R. M. and Fitz, J. G. (1980). The kindling model of epilepsy: a review. Progress in Neurobiology, 15, 139-159.

McNamara, J. O., Rigsbee, L. C. and Galloway, M. T. (1983). Evidence that substantia nigra is crucial to neural network of kindled seizures. European Fournal of Pharmacology, 86, 4856.

Meibach, R. C. and Katzman, R. (1981). Origin, course and termination of dopaminergic substantia nigra neurons projecting to the amygdaloid complex in the cat. Neuroscience, 6 , 2159-2171.

Miller, R. (1984) Major psychosis and depamine: controversial features and some suggestions. Psychological Medicine, 14, 779-789.

Mintz, M. and Herberg, L. J. (1985). Kindling of dopaminergic pathways modifies the effect of substantia nigra lesions on rotational behaviour. Neuroscience Letters, 61, 7-11.

Murugaiah, K., Theodorou, A., Clow, A., Jenner, P. and Marsden, C. D. (1985). Effects of discontinuous drug administration on the development of dopamine receptor supersensitivity during chronic trifluoperazine or cis-flupenthixol administration to rats. Psychopharmacology, 86, 228-32.

Nelson, L. R. and Ellison, G. (1978). Enhanced stereotypes after repeated injections but not continuous amphetamines. Neuropharmacology, 17, 1081-4.

Nevander, G. (1985). "Epileptic brain damage. An experimental study using a recovery model of status epilepticus". Lund.

Ottersen, O. P. (1981). Afferent connections to the amygdaloid complex of the rat with some observations in cats. Fournal of Comparative Neurology, 202, 335-356.

Pert, A., Rosenblatt, J. E., Sivit, C., Pert, C. B. and Bunney, W. E. Jr. (1978). Long term treatment with lithium prevents the development of dopamine receptor supersensitivity. Science, 201, 171-3.

Post, R. M. and Ballenger, J. C. (1981). Kindling models for the progressive development of psychopathology: sentisization to electrical, pharmacological and physiological stimuli. 
In: "Handbook of Biological Psychiatry". H. M. Van Praag, M. H. Lader, O.J. Rafaelsen, E. J. Sachar. Part IV. Marcel Dekker, New York, 1981: 609-51.

Post, R. M. and Rose H. (1976). Increasing effects of repetitive cocaine administration in rat. Nature, 260, 731-2.

Post, R. M., Kopanda, R. T. and Black, K. E. (1976). Progressive effects of cocaine on behaviour and central amine metabolism in rhesus monkeys. Relationship to kindling and psychosis. Biological Psychiatry, 11, 403-19.

Post, R. M., Squillace, K. M., Pert, A. and Sass, W. (1981). The effect of amygdala kindling on spontaneous and cocaine-induced motor activity and lidocaine seizures. Psychopharmacology, 72, 189-196.

Racine, R.J. (1972). Modification of seizure activity by electrical stimulation-II. Motor seizure. Electroencephalography and Clinical Neurophysiology, 32, 281-294.

Racine, R., Gartner, J. G. and Burnham, W. M. (1972). Epileptiform activity and neural plasticity in limbic structures. Brain Research, 47, 262-8.

Rupnaik, N. M. J., Jenner, P. and Marsden, C. D. (1983). The effect of chronic neuroleptic administration on cerebral dopamine receptor function. Life Sciences, 32, 2289-2311.

Sant, W. W. and Ellison, G. (1984). Drug holidays alter onset of oral movements in rats following chronic haloperidol. Biological Psychiatry, 19, 95-99.

Sato, M., Hikosa, N., Tomoda, T., Suemaru, K. and Otsuki, S. (1978). Seizure development and dopamine receptor sensitivity. Folia. Psychiatrica et Neurologica Japonica, 32, 343-344.

Scheel-Krüger, J. (1986). Dopamine-GABA interactions: evidence that GABA transmits, modulates and mediates dopaminergic functions in the basal ganglia and the limbic system. Acta Neurologica Scandinavica, 73 (Suppl 107), 1-54.

Sedvall, G., Forder, L., Persson, A. and Wiesel, F. A. (1986). Imaging of neurotransmitter receptors in the living human brain. Archives of General Psychiatry, 43, 995-1005.

Stein, L. and Wise, C. E. D. (1971). Possible etiology of schizophrenia: progressive damage to the noradrenergic reward system by 6-hydroxydopamine. Science, 171, 1032-1036.

Stevens, J.R. and Livermore, A. Jr. (1978). Kindling of the mesolimbic dopaminergic system: animal models of psychosis. Neurology, 28, 36-46.

Stipling, J. S. and Ellinwood, E. H. (1977). Potentiation of the behavioural and convulsant effects of cocaine by chronic administration in the rat. Pharmacology, Biochemistry and Behavior, 6, 571-9.

Wada, J. A., Sato, M. and Corcoran, M.E. (1974). Persistent seizure susceptibility and recurrence of spontaneous seizure in kindled cats. Epilepsia, 15, 465-478.

Waddington, J. L., Cross, A. J., Gamble, S. J. and Bourne, R. C. (1983). Spontaneous orofacial dyskinesia and dopaminergic function in rats after 6 months of neuroleptic treatment. Science, 220, 530-2.

Waddington, J. L., Molloy, A. G., O'Boyle, K. M. and Youssef, H. A. (1985). Spontaneous and drug-induced dyskinesias in rodents in relation to ageing and long-term neuroleptic treatment: relationship to tardive dyskinesia. In "Biological Psychiatry" (Eds C. Shagass et al.) Elsevier, New York. 1151-1153.

Waddington, J. L., Youssef, H. A., O’Boyle, K. M. and Molloy, A. G. (1986). A reappraisal of abnormal, involuntary movements (tardive dyskinesia) in schizophrenia and other disorders: animal models and alternative hypotheses. In "The Neurobiology of Dopamine Systems" (Eds. W. Window and R. Markstein). Manchester University Press, Manchester, 266 286.

Waszczak, B. L., Lee, E. K., Tamminga, G. A. and Wulters, J. R. (1984). Effect of dopamine system activation on substantia nigra, pars reticulata output neurons: Variable single unit responses in normal rats and inhibition in 6-hydroxy dopamine-lesioned rats. Fournal of Neuroscience, 41, 2369-75.

Weiss, B. and Santelli, S. (1978). Dyskinesias evoked in monkeys by weekly administration of haloperidol. Science, 200, 799-801.

Wilkison, D. M. and Halpern, L. M. (1979). Turnover kinetics of dopamine and norepinephrine in the forebrain after kindling in rats. Neuropharmacology, 18, 219-222. 


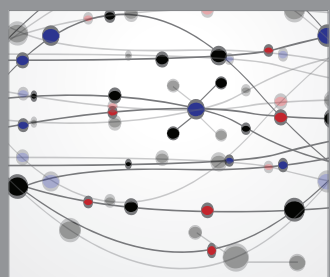

The Scientific World Journal
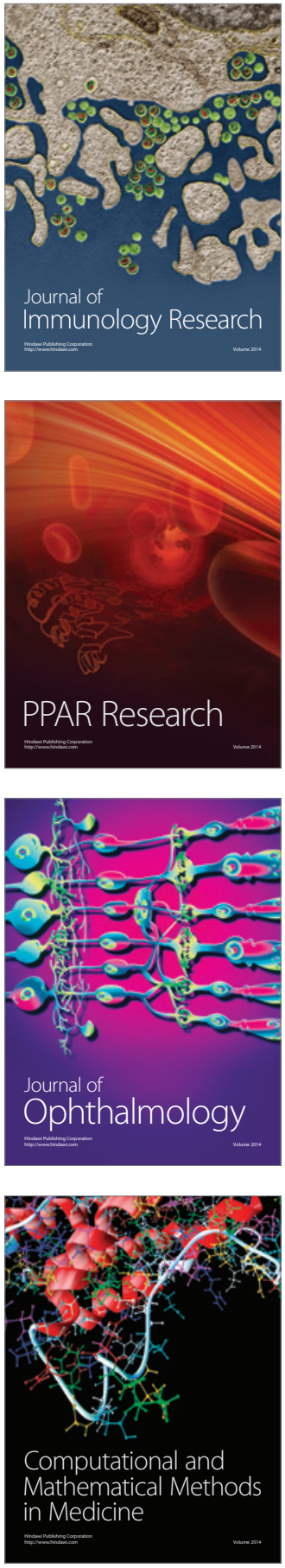

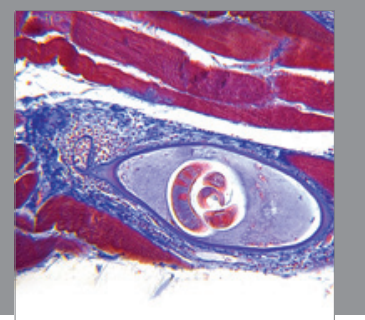

Gastroenterology

Research and Practice
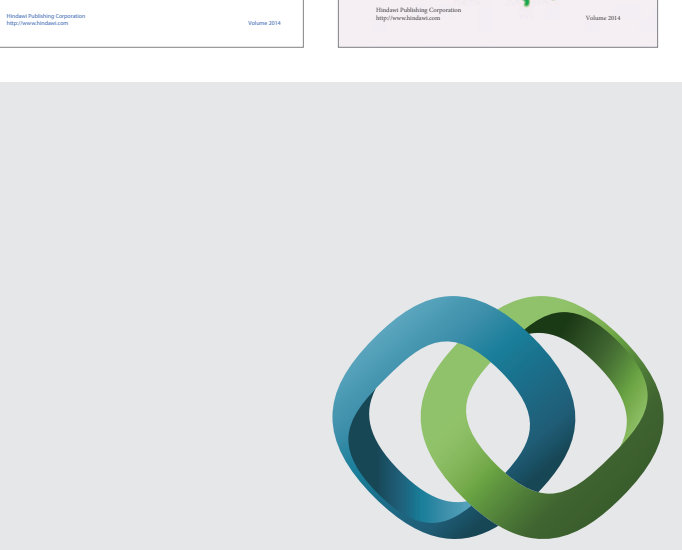

\section{Hindawi}

Submit your manuscripts at

http://www.hindawi.com
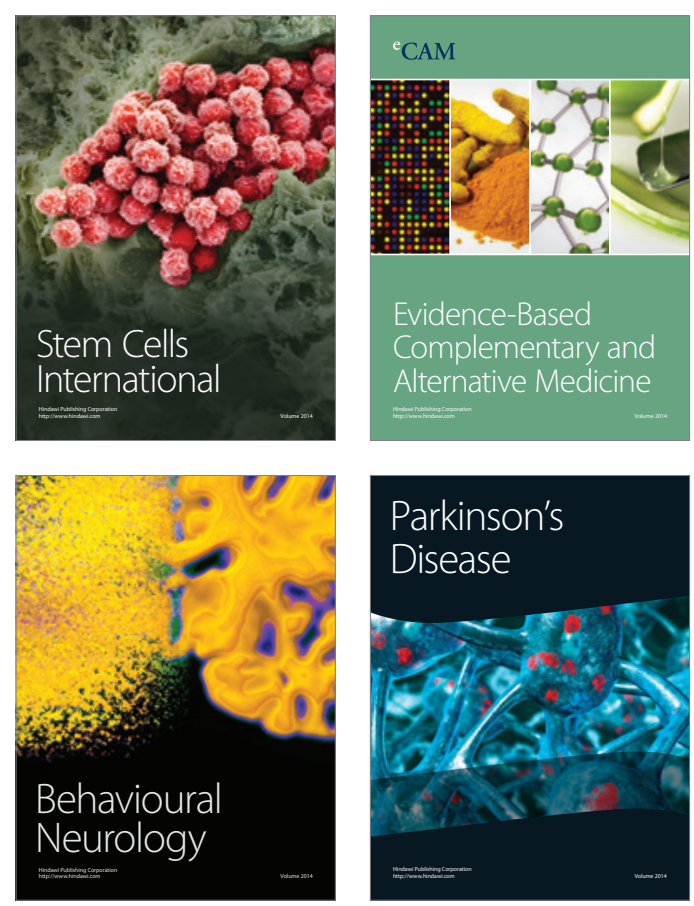

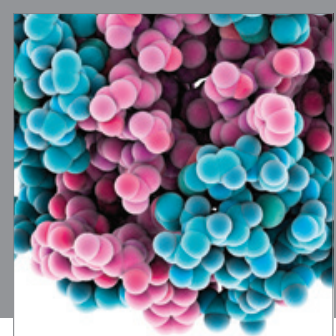

Journal of
Diabetes Research

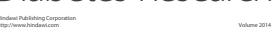

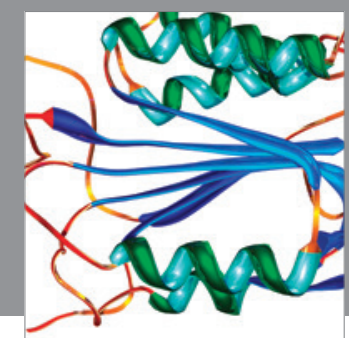

Disease Markers
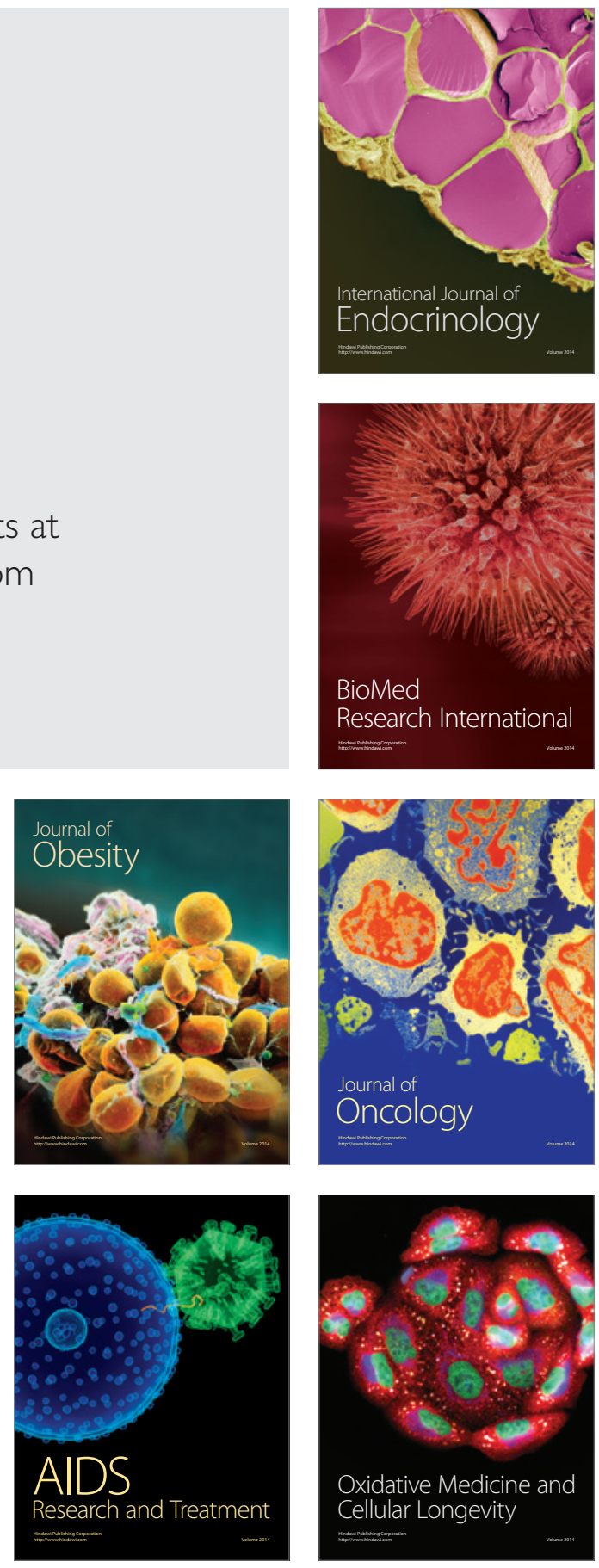